\title{
TARJETAS DE CRÉDITO EN AUMENTO: SOBREENDEUDAMIENTO, ALTO RIESGO ¿LAA REGULACIÓN?
}

Pablo W. Mauricio Pachas*

pwmauricio@yahoo.es

\section{RESUMEN}

En los últimos años, en el Perú, el financiamiento para el consumo mediante la utilización de las Tarjetas de Crédito (TC) ha venido en aumento, permitiendo a muchas personas y familias, el acceso fácil al crédito bancario, lo cual es bueno debido a que de modo inmediato aumenta la disponibilidad para compras de bienes y servicios o para disposición en efectivo, pero por otro lado, eleva las cargas financieras comprometiendo los futuros ingresos, no solo por los nuevos endeudamientos, sino por el alto costo que se aplica a este crédito a través de estos plásticos.

Palabras clave: Costo de la tarjeta.

\section{ABSTRACT}

In recent years in Peru, the financing for consumption through the use of credit cards(TC) has been on the rise, allowing many individuals or families, the easy access to bank credit, which is good because immediately increases the availability for purchases of goods and services or to cash available. But on the other hand increases the financial burden, jeopardizing future income, not only for new loans but the high rate of interest that has been applied this credit.

This consumer credit by using CC have accessed by more than 2 million people since May this year, banks and financial have issued 7,091.523 of CC, which amount used reaches the balance of S/.15, 208 million. The increase in CC is related to the growth of gross domestic product (GDP), which has in turn, is driving the consumption and domestic demand, resulting in increase in personal income and greater access to credit markets and loans in the financial system, behavior that is equally significant as productive to promote the modernization of the country

Although, it is economically favorable to stimulate consumption and to contribute to the growth, but financially for the individuals and families, it is worrying the debt overhang and the high cost of consumer credit, given the current situation characterized by the "International Crisis" that has been generating increasing fears, as the high unemployment in European and the internal risks as the conflicts unresolved. Therefore, a reasonable uncertainty is established and an active action turns out to be necessary on behalf of the Regulation.

Keywords: Cost of the card.

* Doctor en Ciencias Contables y Empresariales, Licenciado en Economía, Docente Principal de la UNMSM, Ex Director de la Unidad de postgrado de la FCA - UNMSM. 


\section{TARJETAS DE CRÉDITO EN AUMENTO}

Tal ha sido el aumento de las TC, que la emisión de estos plásticos por parte de la banca a mayo del presente año ha alcanzado los 7,091,523, aumentando en 49,671 (0.7\%) con relación a abril y en $624,060(9.6 \%)$ con respecto a mayo del 2011, lo que resulta bueno, porque la masificación ha logrado que las personas se interrelacionen con mayor frecuencia con los bancos y financieras que ofertan las TC y puedan comparar estos servicios con los que ofrecen entidades informales no comprendidos en el Sistema Financiero Nacional. Sin embargo, surge la preocupación al preguntarnos ¿Qué conlleva el aumento significativo de las TC? La respuesta es sobreendeudamiento que conlleva al alto riesgo de insolvencia. Tal evolución de la emisión de las TC a mayo del 2012 se puede observar en el siguiente gráfico.

Gráfico 01: Tarjetas de Crédito de Bancos y Financieras (Fuente SBS).

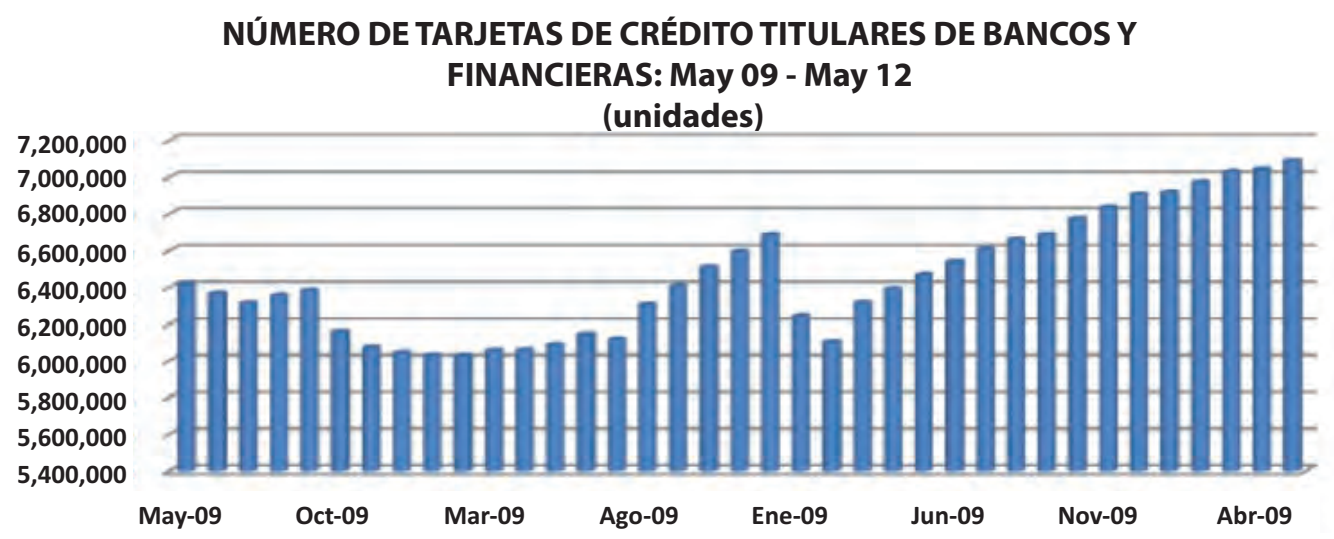

A este crédito de consumo, mediante el uso de las TC emitido por bancos y financieras, han accedido más de 2 millones de personas y según ASBANC, a mayo del presente año (2012), el monto utilizado a través de tarjetas de crédito, registró un saldo de S/. 15,208 millones, cifra mayor en S/. 458 millones (3.10\%) con respecto a abril y en S/. 3,153 millones equivalente a $26.16 \%$ con relación a mayo de 2011 . Tal evolución del monto utilizado mediante la utilización de las TC a mayo del 2012 se puede observar en el siguiente gráfico.

Gráfico 02: Monto utilizado de Tarjetas de Crédito de Bancos y Financieras. (Fuente SBS).

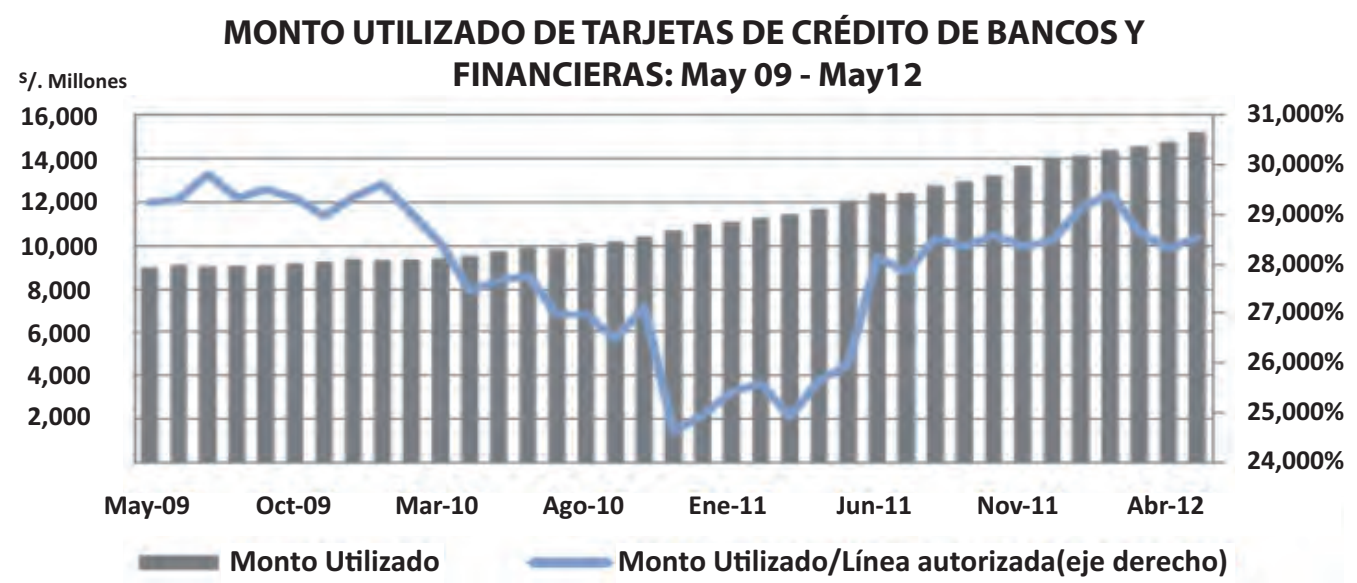

También cabe advertir que la morosidad aumenta aunque en bajo nivel, así la morosidad para este tipo de crédito de consumo mediante la TC levemente ha aumentado a mayo del presente año al alcanzar $4.33 \%$ superior a $4.19 \%$ en marzo y $3.7 \%$ en mayo del 2011 ; sin embargo, está por encima de los créditos de consumo que registraron una morosidad del $2.6 \%$ en diciembre del 2011 y muy superior a 
la morosidad de los créditos bancarios que registraron una morosidad a mayo del presente año (2012) $1.72 \%$ levemente superior a diciembre del 2011 que estuvo en $1.47 \%$ en menos del 0.02 con respecto a diciembre del 2010. Tal evolución de la morosidad de las TC a mayo del 2012 se puede observar en el siguiente gráfico.

Gráfico 03: Morosidad de Tarjetas de Crédito de Bancos y Financieras. (Fuente SBS).

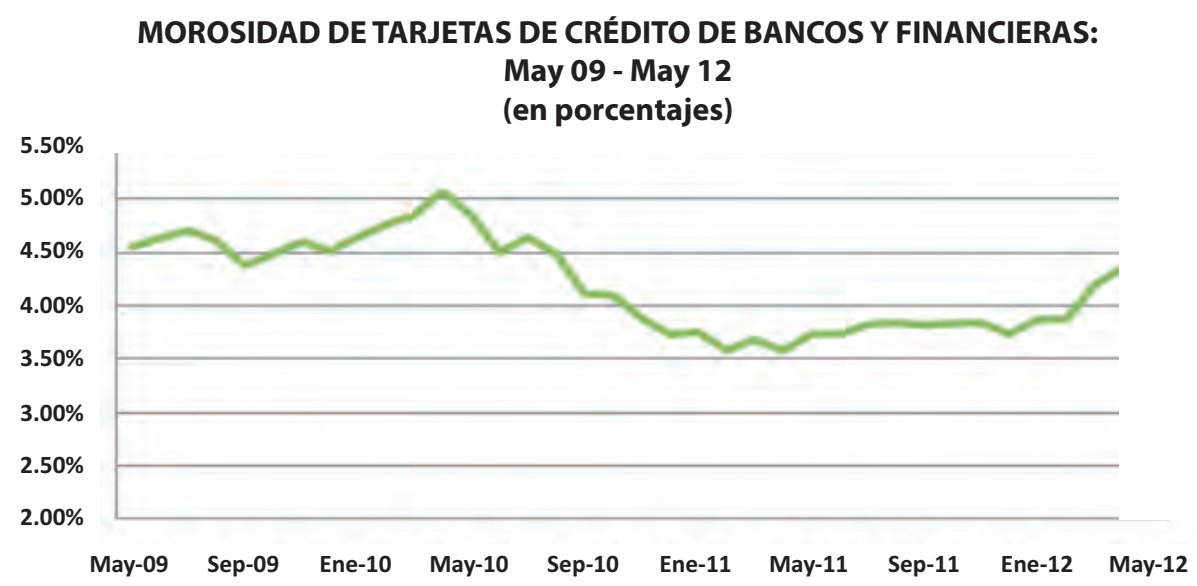

\section{CONSUMO Y CRECIMIENTO}

La relación crecimiento y consumo en los últimos años ha descrito un círculo virtuoso, al observarse que el consumo se ha incrementado en relación con el crecimiento, destacando en este incremento el factor financiamiento de consumo brindado por los Bancos y Financieras,siendo sobresaliente, el crédito a través de las Tarjetas de Crédito (TC) descrito en el punto anterior, que también ha tenido una relación directa con el incremento del PBI. Tal importante crecimiento que vino a experimentar nuestro país a partir de la década de los 90 fue al ponerse en marcha la apertura de la economía y la liberalización de los mercados, cuyo crecimiento sostenido se inicia desde 1993 hasta nuestros días. Apreciación de tal senda de crecimiento sostenido desde 1994, se describe en el siguiente gráfico:

Gráfico 04: Producto Bruto Interno 1994-2011-A valores constante de 1994 (Fuente INEI)

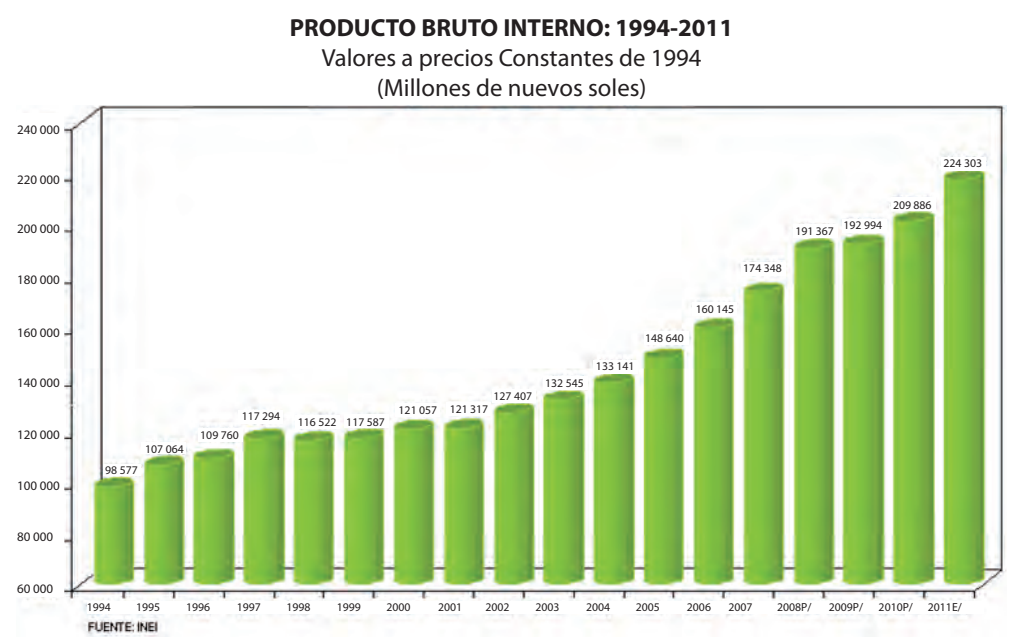

Es decir el crecimiento se explica por el cambio en el modelo económico que adopta el país a partir del año 1990, en que se emprende nuevas políticas económicas y con la de apertura económica, comercial y liberalización de los mercados se propicia la atracción de las inversiones privada. Crecimiento que conllevó a mayores ingresos de las personas e impulsó el consumo. Marcado inicio del crecimiento se puede apreciar desde 1993 en que se alcanza 4.8\%, cerca de 5\% de crecimiento del PBI para ubicarse en 6.9 \% en el 2011. Evolución del crecimiento en 1993 a la actualidad, se observa en el siguiente gráfico. 


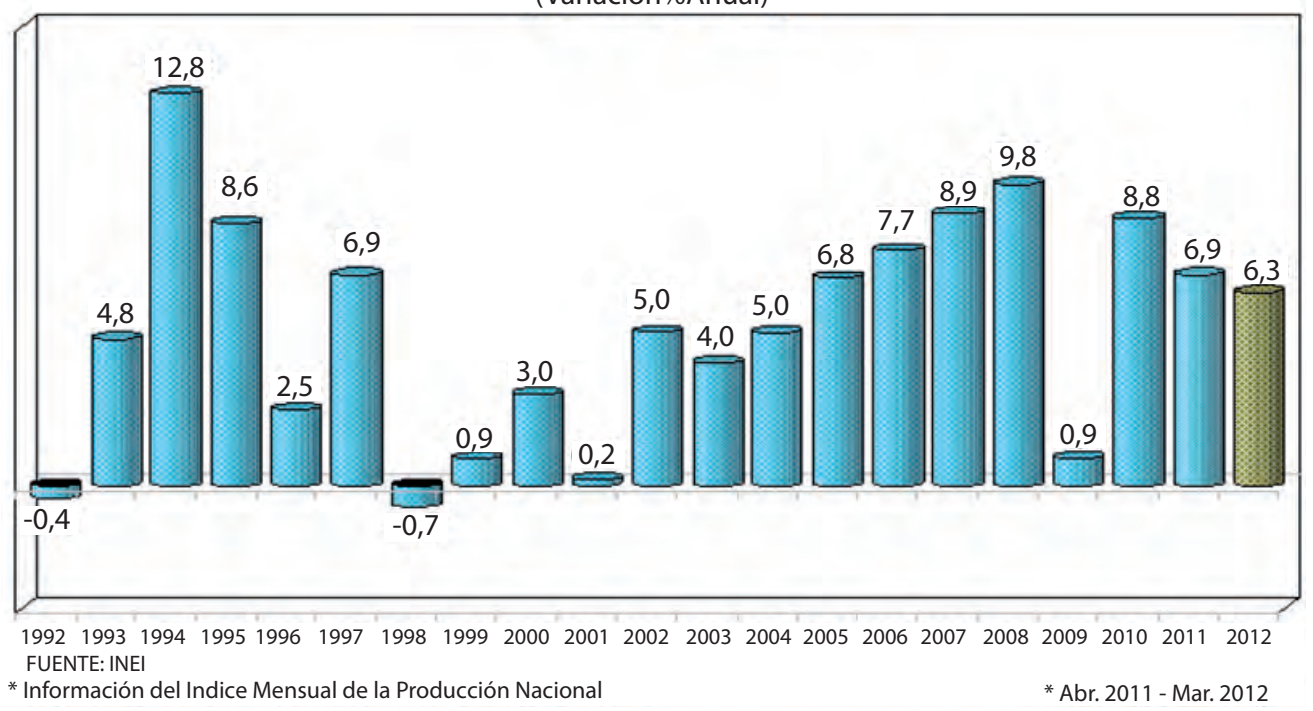

En la virtuosa senda del crecimiento del Producto Bruto Interno (PBI), se evidencia el impacto del crecimiento en el consumo, y a su vez el impulso en la demanda interna, generando aumento en los ingresos de las personas y mayor acceso al mercado, permitiendo, de esta manera, que más accedan a créditos del sistema financiero y se produzca el aumento de las TC, ya descrito. Tal comportamiento resulta igualmente productivo ya que al impulsarse el consumo ha impulsado la modernización del país, como ha venido apreciándose en los últimos tiempos, en que emergen modernos negocios de retail (ventas al detalle) en Lima y fuera de Lima, como ocurre que en cada ciudad importante del país cuenten con grandes centros comerciales y otros en construcción, gracias a la masificación del crédito de consumo, mediante el uso del dinero plástico, lo que resulta saludable destacarlo.

Es así que el aumento de las TC, resulta económicamente favorable al impulsar el consumo y contribuir con el crecimiento, pero financieramente para las personas y familias resulta preocupante, dada la coyuntura caracterizada por la "Crisis Internacional" que viene generando cada vez mayores temores, como el elevado desempleo en Europa", surge una natural pregunta ¿Qué pasa si pierdo mi empleo? la respuesta es que no podría pagar mis compromisos, como el crédito por TC, preocupación valida. Si se añade los riesgos internos como la postergación de las inversiones mineras, debido a conflictos sin solución por parte del gobierno, se establece una razonable incer- tidumbre y riesgo de interrumpir la corriente de ingresos-sueldos y salarios futuros (flujo de caja futuro) ante una eventual caída del PBI. De modo que de los efectos de la globalización no podemos excluirnos, ni de la incertidumbre interna, por lo que resulta necesaria una actuación activa de la regulación, a cargo de la Superintendencia de Banca y Seguros (SBS).

En este sentido, nos preguntamos ¿qué está haciendo la regulación ante el sobreendeudamiento y el elevado costo del crédito de consumo? La respuesta es indiferencia de la SBS. Como lo describiremos más adelante, el crédito más costoso del sistema financiero nacional, es la correspondiente a la utilización de las TC al que se aplican las más altas tasas de interés del mercado. Si nos formulamos otra pregunta cómo ¿Qué medidas se está adoptando para hacer frente ala masificación del crédito a través de las TC? Al parecer, nada, y la regulación está mirando a otro lado. No olvidemos que existe elevada informalidad, escasa cultura financiera y no buen manejo de los ingresos y gastos, afectando el cuidado del crédito bancario. Situación que ante el sobreendeudamiento caro, conllevaría al alto riesgo de caer en la insolvencia, afectando la cadena de pagos.

\section{EL CRÉDITO Y LA TASA DE INTERÉS}

Los costos de los créditos y los rendimientos de los depósitos de ahorros, están expresados en tasas de interés, por lo que resulta importante, conocer cuál es la tasa de interés del préstamo. 
antes de endeudarse. Actualmente por disposición de la SBS, los bancos en Instituciones del sistema financiero vienen publicando las diferentes tasas de interés que se aplican a las diferentes modalidades de préstamos bancarios y depósitos de ahorros. Para una mejor comprensión describiremos algunos conceptos importantes.

Dinero y valor. El dinero es un signo expresado en moneda o billete- papel, que toda persona o agente económico utiliza como medio de pago en los diferentes mercados, facilitando las transacciones de diferentes bienes, servicio, factores, capitales, etc., de modo que en la vida cotidiana de las familias, empresas y gobierno es un recurso esencial para acceder a los mercados y desarrollar las diferentes actividades económicas. El dinero en la economía, sirve como medio de cambio, unidad de cuenta y depósito de valor.

El dinero por sí mismo no crea valor, por el contrario, pierde poder adquisitivo, debido a que las mercancías, bienes o activos materia de transacción en una economía de mercado varían permanentemente de precios (inflación). Estas mercancías o activos son los únicos recursos que permiten mantener o incrementar el poder adquisitivo del dinero durante el tiempo. Es decir la prontitud de la inversión de dinero en mercancías o activos hará aumentar su valor o, en caso contrario, la demora hará disminuir tal valor, estableciéndose de este modo al tiempo como factor del valor del dinero, valor que será expresado en tasa de interés.

Actualmente, las nuevas tecnologías y la globalización económica están promoviendo el mayor uso del dinero plástico y dinero electrónico, impulsando la creación del dinero, a través de los intermediarios financieros que reciben los depósitos de los diferentes agentes económicos y los colocan mediante préstamos o deferentes modalidades de créditos, intermediarios conocidos como Bancos y Financieras.

Dinero y finanzas personales. Últimamente, se viene apreciando en el comportamiento de las personas, un mayor cuidado por el buen destino de su dinero, percibido cuando se reciben los sueldos, intereses, dividendos, etc. Las personas consultan a especializados para tomar decisiones de compra de bienes duraderos y evalúan en qué invertir, ya que los ahorros en bancos no son atractivos por sus bajos rendimientos y estar inmerso en una inflación aún cuando se registren bajas tasas. Las familias se enfrentan a muchas decisiones, como por ejemplo, comprar un auto nuevo, usado o alquilarlo, adquirir un crédito para comprarse una casa o ampliar la misma o realizar estudios. Es así como se dan las finanzas personales, para ayudar a tomar las mejores decisiones en el destino de los ingresos, ahorros y accesos al financiamiento, destacándose la importancia de la información. Ocurre que cada mes cuando recibimos nuestros ingresos nos preocupamos ¿en qué gastarlos? Inmediatamente reflexionamos y asumimos un comportamiento de análisis y de evaluación que nos conlleva a preguntarnos ¿Qué nos conviene? Respuesta, atender lo más importante, surge así, la priorización de las obligaciones o necesidades de acuerdo a objetivos deseados, luego los alcances del planeamiento financiero, la contabilidad, control y finanzas. Estas mismas herramientas que son utilizadas por las empresas pueden ser utilizadas por las personas con el fin de maximizar el retorno de sus inversiones, mejor manejo de sus ingresos y gastos de su dinero.

La tasa de interés y diferentes denominaciones en el sistema financiero nacional (SFN). La tasa de interés en el SFN se expresan de acuerdo al criterio contable y según las principales cuentas del balance general. Estas cuentas corresponden a los activos y pasivos, las primeras están relacionadas a las posesiones o derechos sobre bienes o mercancías y las cuentas del pasivo que están relacionadas a las obligaciones contraídas con terceros. En este sentido, las tasas de interés en el SFN se agrupan en tasas activas y pasivas, utilizadas por las instituciones bancarias y financieras. Las tasas activas corresponden a los costos financieros a cobrar por operaciones de crédito, como préstamos, pagarés, sobregiros, etc. surgiendo también los costos promedio como la TAMN, tasa activa promedio en moneda nacional (nuevos soles) y la TAMEX, tasa activa promedio en moneda extranjera (dólares). De otro lado, las tasas pasivas corresponden a los rendimientos a pagar por operaciones de ahorros, captaciones de depósitos, como certificado de ahorro a plazo, etc. surgiendo así también la TIPMN, tasa pasiva promedio en moneda nacional (nuevos soles) y la TIPMEX, tasa pasiva promedio en moneda extranjera (dólares). Según el cumplimiento de la obligaciones podrán determinarse, tasa compensatoria y tasa moratoria. Otras tasas están relacionadas a la tasa nominal, tasa real, tasa de interés legal, la TCEA, tasa de costo efectivo anual que comprende el interés acordado más otros gastos bancarios, la TREA, tasa de rendimiento efectivo anual, etc. 


\section{CONCENTRACIÓN DE CRÉDITOS Y DEPÓSITOS EN EL SISTEMA BANCARIO PERUANO}

Los créditos y los depósitos en el sistema bancario peruano están concentrados en pocos bancos, como la participación de más del $50 \%$ de los créditos corresponden a dos bancos y el mayor volumen de los créditos colocados y depósitos captados corresponden a cuatro bancos, lo que explica la elevada capacidad que tienen estos bancos en la determinación de la tasa de interés y, por supuesto, el dominio del mercado.

Los créditos o préstamos en el sistema financiero nacional son ofertados significativamente por los bancos, resultando importante señalar la participación de los bancos en tal concentración. Así en las operaciones de préstamos bancarios, 4 bancos concentran el $83.49 \%$ de los créditos. Tal participación de los 4 bancos en los créditos a mayo del presente año, se puede observar en el siguiente cuadro.

Cuadro 01: Créditos Directos de Bancos (En miles de nuevos soles) Al 31 de mayo de 2012 (Fuente SBS)

\begin{tabular}{|c|c|c|c|c|}
\hline & Bancos & Monto & $\begin{array}{c}\text { Participación } \\
(\%)\end{array}$ & $\begin{array}{l}\text { Porcentaje } \\
\text { Acumulado }\end{array}$ \\
\hline 1 & B. de Crédito del Perú & $44,813,324$ & 33.66 & 33.66 \\
\hline 2 & B. Continental & $31,834,629$ & 23.91 & 57.57 \\
\hline 3 & Scotiabank Perú & $19,861,587$ & 14.92 & 72.49 \\
\hline 4 & Interbank & $14,643,405$ & 11.00 & 83.49 \\
\hline 5 & Mibanco & $4,409,014$ & 3.31 & 86.80 \\
\hline 6 & B. Interamericano de Finanzas & $3,818,654$ & 2.87 & 89.67 \\
\hline 7 & B. Financiero & $3,291,243$ & 2.47 & 92.14 \\
\hline 8 & HSBC Bank Perú & $2,474,675$ & 1.86 & 94.00 \\
\hline 9 & Citibank & $2,191,540$ & 1.65 & 95.64 \\
\hline 10 & B. Falabella Perú & $1,972,300$ & 1.48 & 97.12 \\
\hline 11 & B. Santander Perú & $1,263,000$ & 0.95 & 98.07 \\
\hline 12 & B. de Comercio & $1,183,588$ & 0.89 & 98.96 \\
\hline 13 & B. Ripley & 990,793 & 0.74 & 99.71 \\
\hline 14 & B. Azteca Perú & 392,412 & 0.29 & 100.00 \\
\hline 15 & Deutsche Bank Perú & - & - & \\
\hline
\end{tabular}

De otro lado, los mayores volúmenes de depósitos en el SFN corresponden, igualmente a 4 Bancos que concentran el $\mathbf{8 2 . 6 0 \%}$ del total de los depósitos, destacándose la capacidad de estos bancos en el control de las tasas. Tal participación de los 4 bancos en los depósitos a mayo del presente año, se puede observar en el siguiente cuadro.

Cuadro 02: Depósitos Totales de Bancos (En miles de nuevos soles) Al 31 de mayo de 2012 (fuente SBS)

\begin{tabular}{llccc}
\hline \multicolumn{1}{r}{ Bancos } & Monto & Participación & Porcentaje \\
& & & $(\%)$ & Acumulado \\
& & & & \\
1 & B. de Crédito del Perú & $46,785,779$ & 35.15 & 35.15 \\
2 & B. Continental & $30,941,054$ & 23.25 & 58.40 \\
3 & Scotiabank Perú & $17,663,139$ & 13.27 & 71.67
\end{tabular}




$\begin{array}{llccc}4 & \text { Interbank } & 14,536,918 & 10.92 & 82.60 \\ 5 & \text { B. Interamericano de Finanzas } & 4,170,078 & 3.13 & 85.73 \\ 6 & \text { Mibanco } & 3,660,953 & 2.75 & 88.48 \\ 7 & \text { HSBC Bank Perú } & 3,424,152 & 2.57 & 91.05 \\ 8 & \text { Citibank } & 3,178,311 & 2.39 & 93.44 \\ 9 & \text { B. Financiero } & 3,014,816 & 2.27 & 95.71 \\ 10 & \text { B. Santander Perú } & 1,832,010 & 1.38 & 97.08 \\ 11 & \text { B. de Comercio } & 1,329,189 & 1.00 & 98.08 \\ 12 & \text { B. Falabella Perú } & 1,145,432 & 0.86 & 98.94 \\ 13 & \text { B. Ripley } & 735,362 & 0.55 & 99.49 \\ 14 & \text { B. Azteca Perú } & 416,835 & 0.31 & 99.81 \\ 15 & \text { Deutsche Bank Perú } & 255,626 & 0.19 & 100.00\end{array}$

\section{TASAS DE INTERÉS Y ELEVADOS MÁRGENES-SPREAD DE BANCOS EN EL PERÚ}

La tasa de interés y sus diferentes denominaciones descritas en el punto III, vamos a retomar a la tasa activa y pasiva promedio relacionada a los préstamos y a los depósitos. Así la TAMN,tasa activa promedio en moneda nacional (nuevos soles) y la TAMEX, tasa activa promedio en moneda extranjera (dólares) y, de otro lado, TIPMN,tasa pasiva promedio en moneda nacional (nuevos soles) y la TIPMEX,tasa pasiva promedio en moneda extranjera (dólares), permitirá establecer las diferencias o márgenes denominados spread que en el SFN, son elevados.

La evolución de las tasas en nuestro país, han venido describiendo elevados márgenes o spread, determinadas por la diferencia de las tasas cobradas por los préstamos y las tasas pagadas por los depósitos de ahorros, que al establecerse los elevados márgenes, se explican los altos costos financieros que vienen aplicando los bancos a los préstamos o créditos bancarios.

Así, los márgenes denominados spread desde 1992, han disminuido al comparar con el año 1993 y 1995, pero luego se mantiene en niveles altos como se puede observar en el margen del año 2000 con respecto al año actual (2012), que de $\mathbf{2 2 . 6 3 \%}$ pasa a $\mathbf{1 7} \%$ respectivamente en moneda nacional, y para el caso de dólares de $\mathbf{7 . 8 6} \%$ en 2000 pasa a 7.24\% en el presente año, manteniendo su nivel. Tal evolución de los Spread de 1992 a julio del 2012, se puede observar en los cuadros siguientes:

Cuadro 03: Márgenes en Moneda Nacional Cuadro 04: Márgenes en Moneda Extranjera

\section{ELEVADOS MÁRGENES EN MONEDA EXTRANJERA PERIODO 1992-2012}

\begin{tabular}{|c|c|c|c|}
\hline AÑO & TAMEX & TIPMEX & SPREAD \\
\hline 1992 & $16.90 \%$ & $5.78 \%$ & $11.12 \%$ \\
\hline 1993 & $15.2 \%$ & $5.00 \%$ & $10.20 \%$ \\
\hline 1994 & $15.20 \%$ & $4.90 \%$ & $10.30 \%$ \\
\hline 1995 & $17.20 \%$ & $6.20 \%$ & $11.10 \%$ \\
\hline 1996 & $16.80 \%$ & $5.70 \%$ & $11.10 \%$ \\
\hline 1997 & $15.60 \%$ & $5.20 \%$ & $10.40 \%$ \\
\hline 1998 & $16.80 \%$ & $5.40 \%$ & $11.40 \%$ \\
\hline 1999 & $14.46 \%$ & $4.84 \%$ & $9.62 \%$ \\
\hline 2000 & $12.46 \%$ & $4.60 \%$ & $7.86 \%$ \\
\hline $2012\left(^{*}\right)$ & $8.70 \%$ & $0.83 \%$ & $7.24 \%$ \\
\hline
\end{tabular}

ELEVADOS MÁRGENES EN MONEDA NACIONAL PERIODO 1992-2012

\begin{tabular}{|c|c|c|c|}
\hline AÑO & TAMN & TIPMN & SPREAD \\
\hline 1992 & $135.50 \%$ & $18.15 \%$ & $117.35 \%$ \\
\hline 1993 & $71.50 \%$ & $18.20 \%$ & $53.30 \%$ \\
\hline 1994 & $39.00 \%$ & $7.30 \%$ & $31.70 \%$ \\
\hline 1995 & $35.10 \%$ & $9.90 \%$ & $25.20 \%$ \\
\hline 1996 & $30.06 \%$ & $10.50 \%$ & $19.56 \%$ \\
\hline 1997 & $30.04 \%$ & $9.90 \%$ & $20.14 \%$ \\
\hline 1998 & $32.06 \%$ & $12.60 \%$ & $19.46 \%$ \\
\hline 1999 & $32.33 \%$ & $10.49 \%$ & $21.46 \%$ \\
\hline 2000 & $32.33 \%$ & $9.70 \%$ & $22.84 \%$ \\
\hline $2012\left(^{*}\right)$ & $19.50 \%$ & $2.50 \%$ & $17.00 \%$ \\
\hline
\end{tabular}


Es decir, el spread en el Perú es altísimo y los créditos bancarios en el Perú son caros, no obstante que el país cuenta con un reconocimiento internacional (S\&P, Fitch, Moody's) de grado de inversión, lo que conlleva a que los instrumentos en el mercado financiero peruano sean considerados de bajo riesgo y en consecuencia las tasas de interés para los créditos bancarios deberían bajar y estar muy por debajo de las actuales. Es por ello que nuevamente nos preguntamos ¿Qué está haciendo la SBS? La respuesta, la SBS es indiferente. ¿Son elevadas las tasas que se cobran por los préstamos bancarios en el Perú? Sí.

Son elevadas las tasas de interés que se aplican a los préstamos en el SFN, al compararlas con las bajas tasas que se revelan en los mercados internacionales. Ante la crisis internacional, las tasas internacionales para préstamos han venido descendiendo a niveles bajo, como ocurre con la Tasa Libor Activa Promedio de $\mathbf{0 . 7 6 3 \%}$ a abril del presente año (2012), la tasa anual Libor del dólar USA de $1.05 \%$ y la Tasa anual Libor del EURO de 1.27 \%. Otra referencia, según el Banco Mundial (BM) el Perú en el 2010 tuvo un elevado spread del 17.5\% (similar al 17\% actualmente), diferencia de la tasa activa promedio de $19 \%$ y la pasiva de1,5\%, ubicando a nuestro país en el décimo lugar entre los países con mayor spread del mundo (Peor spread) por encima de Haití, Honduras, Zambia y otros con graves problemas económicos e inestabilidad política y social, y que tienen un spread más bajo que el Perú. En tanto, los países con menores spread, con tasas del $4 \%$ y menos esta México, Chile y otros.

Tal descripción de Países con mayores y menores spread, se detallan en los gráficos siguientes:

Gráfico 06: Países y tasas de interés de Depósitos y Préstamos. (Año 2010)

TASAS DE DEPÓSITO Y DE PRÉSTAMO (PAÍSES CON PEOR SPREAD)

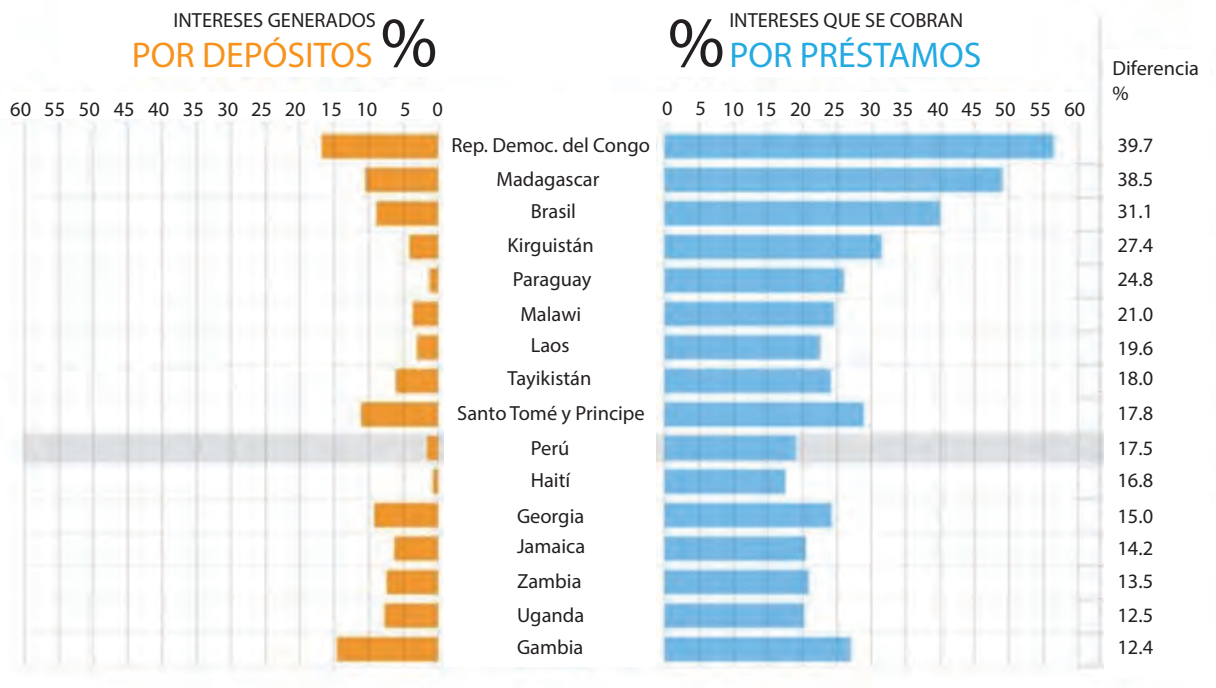

TASAS DE DEPÓSITO Y DE PRÉSTAMO (PAÍSES CON MEJOR SPREAD)

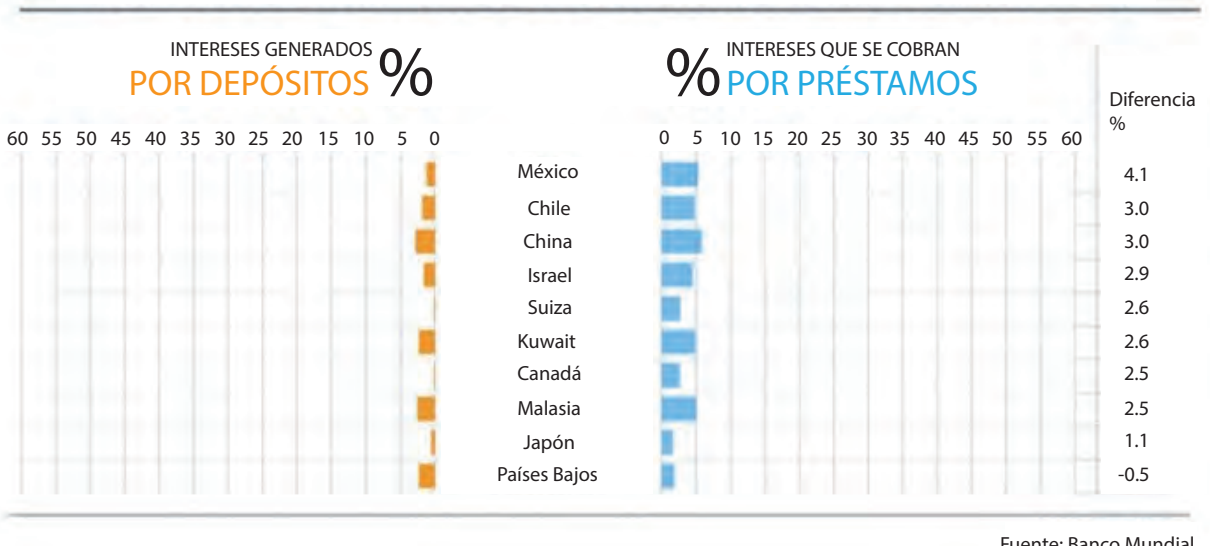




\section{ELEVADA TASA DE INTERÉS PARA PRÉSTAMOS DE CONSUMO}

Las tasas que se cobran por préstamos en soles como en dólares están diferenciadas por tipo de operaciones, siendo las más bajas para operaciones corporativos y las más elevadas para operaciones de consumo. Así observamos que las tasas a enero del presente año, para operaciones con corporativas

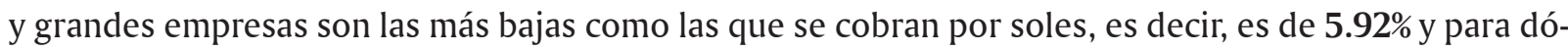
lares de $3.5 \%$ y las tasas más altas son para operaciones de consumo como la de $37.68 \%$ para soles y de 22.27\% para dólares en promedio, ya que a los clientes de menor solvencia se le aplica una tasa mayor. Tales tasas por tipo de crédito al 27 de enero del 2012 se observa en el siguiente cuadro (Fuente SBS).

Cuadro 05: Tasas por tipo de Crédito en Moneda Nacional y Extranjera

\begin{tabular}{|l|c|c|}
\hline \multicolumn{3}{|c|}{ Tasas Activas Anuales de las Operaciones. Tipo de Crédito al 27/01/2012 } \\
\hline & Moneda Nacional & Moneda Extranjera \\
\hline Corporativos & $5.92 \%$ & $3.50 \%$ \\
\hline Grandes Empresas & $7.47 \%$ & $5.41 \%$ \\
\hline Medianas Empresas & $11.34 \%$ & $9.03 \%$ \\
\hline Pequeñas Empresas & $22.83 \%$ & $15.41 \%$ \\
\hline Microempresas & $32.91 \%$ & $18.84 \%$ \\
\hline Consumo & $37.68 \%$ & $22.27 \%$ \\
\hline Hipotecarios & $9.38 \%$ & $8.28 \%$ \\
\hline
\end{tabular}

Mercados Financieros. Están determinados por la oferta y demanda de "instrumentos financieros" denominados también "productos financieros" que representan a medios representativos de dinero y de capital y que mediante la negociación se establece el precio expresado en la tasa de interés. Estos son transados entre agentes económicos superavitarios (con excedentes de recursos) y deficitarios (con necesidades de recursos) de acuerdo a determinadas tasas de interés. Su principal ventaja de los mercados es ser transparentes, libres, amplios, abiertos e integrados, permiten la interconexión de los ofertantes y demandantes de recursos financieros, a través de Instituciones, normas, costumbres y prácticas de personas que intervienen en la canalización de recursos financieros. Los agentes superavitarios, ofertan sus excedentes (ahorro > inversión) obteniendo activos financieros (prestamista de fondos) o bien reducen sus pasivos amortizando sus instrumentos financieros (deudas). Mientras tanto, los agentes deficitarios demandan recursos financieros (inversión $>$ ahorro) a través de instrumentos financieros (prestatario de fondos) o bien reducen sus activos vendiendo sus derechos.

Las transacciones de diversos instrumentos determinan los activos y pasivos financieros entre los agentes superavitarios y deficitarios y se desarrollan a través de los flujos de fondos mediante la intermediación en los mercados, ya sea el mercado de dinero, el mercado de capitales y mercado de derivados

El mercado de dinero comprende la oferta y demanda fondos de corto plazo, orientados a cubrir necesidades inmediatas y de carácter temporal como gastos operativos, en este mercado intervienen activamente los bancos y las demás instituciones financieras. El mercado de capitales, comprende las transacciones de instrumentos de mediano y largo plazo, de allí su denominación de "instrumentos representativo de capital y de deudas", destinados a inversiones como infraestructura, reposición de bienes de capital o proyectos, lo que implica un periodo de maduración para el retorno del capital invertido.

El Sistema Financiero Nacional está conformado por las instituciones reguladoras, supervisora e intermediarios, cuyo rol es el desarrollo de la intermediación de acuerdo a la normas, costumbres y prácticas reglamentadas impulsando la canalización de los recursos de los agentes superavitarios a los agentes deficitarios a través de los mercados, facilitando el desarrollo del proceso ahorro - inversión, y a la actividad económica del país. Los intermediarios financieros transforman fondos para hacerlos más atractivos, proporcionan una gran variedad de servicios denominados instrumentos financieros o productos financieros. 
El SFN comprende: Banco Central de Reserva del Perú (BCR), Superintendencia de Banca y Seguros (SBS) superintendencia del mercado de valores (SMV), Bancos, Financieras y Micro financieras, etc.

El SFN vincula a los agentes económicos de la economía doméstica y del mercado internacional mediante el sistema de intermediación Indirecta que corresponde al mercado de dinero y sistema de intermediación directa que corresponde al mercado de valores (capitales). En este caso estamos tratando el comportamiento de la intermediación indirecta y las tasas de los préstamos bancarios, así como la tasa de interés que se cobran por los créditos de consumo y por el uso de la TC.

Acerca de la reciente reglamentación. La reciente modificación al reglamento de transparencia publicada por la SBS, determina cuatro nuevos conceptos que las entidades financieras no podrán cobrarle a sus clientes, siendo el primero, cobrar una comisión cuando los clientes realicen el prepago de sus créditos, de manera que los usuarios del sistema financiero podrán pagar por adelantado sus cuotas o cancelar el total de sus deudas sin que las entidades financieras le cobren un cargo por ello.

Los tres restantes nuevos conceptos prohibidos de cobrarse son el cargo por evaluación y administración de las garantías vinculadas a los créditos hipotecarios de viviendas; así como a los cargos por la remisión de depósitos al fondo de seguro de depósitos y por último, los cargos por la emisión y por la entrega de la primera constancia de no adeudo por la cancelación de un crédito.

De este modo, la SBS ha identificado un total de 15 conceptos que las entidades financieras están prohibidas de cobrarles a los usuarios del sistema financiero como comisiones o cargos. En el reglamento de transparencia anteriormente vigente, la SBS ya había identificado 11 conceptos, los mismos que se dejaron de cobrar, entre ellos destacan la comisión por el desembolso de un crédito, los cargos por evaluación crediticia del cliente, y los cargos por la emisión y entrega de la constancia de la situación crediticia del deudor, cuando la empresa bancaria hubiera efectuado un reporte erróneo a la central de riesgos.
ELEVADA TASA DE INTERÉS APLICADA A LAS TARJETAS DE CRÉDITO

Como hemos descrito en las tasas de interés aplicada por tipo de operaciones en el SFN, las tasas que se cobran para créditos de consumo son las más caras, en que para soles, alcanza $\mathbf{3 7 . 6 8 \%}$ en promedio, sin embargo, las que se aplican a las TC resultan ser mucho mayor, que al considerar la tasa de costo efectivo anual (TCEA) de publicación oficial, alcanza a $\mathbf{1 0 0 . 6 3} \%$ como tasa máxima en nuevos soles (HSBC) y mínima $27.27 \%$, dependiendo de los bancos. De manera que la carga del endeudamiento asumida por las personas o familias es significativamente mayor por el coto financiero y eleva el riesgo del endeudamiento e incumplimiento.

Incumplimiento en el pago de las tarjetas de créditos. Como se ha destacado las bondades de la utilización de las TC para las familias y para la economía peruana, ahora cabe destacar una alerta, como los signos de atrasos en los pagos del crédito a través de la TC, descrito en el $\mathbf{1 2} \%$ de los dos millones de personas con acceso a este crédito, están incumpliendo con sus compromisos de pago mínimo y se encuentran con alerta roja, significando riesgo crediticio deficiente, dudoso o eventual pérdida. Según una central de riesgo, el $\mathbf{1 8 \%}$ se encuentran con deudas vencidas, consideradas problema potencial.

Las altas tasas para consumos mediante TC por bancos se puede observaren el siguiente Cuadro A. De otro lado, la más cara aún, es por retiro de efectivo de la TC, cuyo costo se eleva considerablemente, alcanzando $188.16 \%$ (HSBC) descrito en el Cuadro B: Disposición de Efectivo.

Si bien el auge de las TC ha impulsado el consumo y, por el momento, resulta manejable para la banca seguir otorgando más créditos de consumo mediante la TC, debido a que cuenta con elevada liquidez para realizar provisiones, esto no significa que se debe desentender que estamos inmerso en una "crisis internacional" e incertidumbre en la dinámica de las inversiones a nivel interno. Situación que conlleva a una preocupación de cómo tratar el sobreendeudamiento? dado que el impacto de la "Crisis Internacional" y la incertidumbre interna, es inevitable, lo que afectaría el crecimiento y los ingresos de las personas, por lo que se requiere una actuación activa de la regula- 


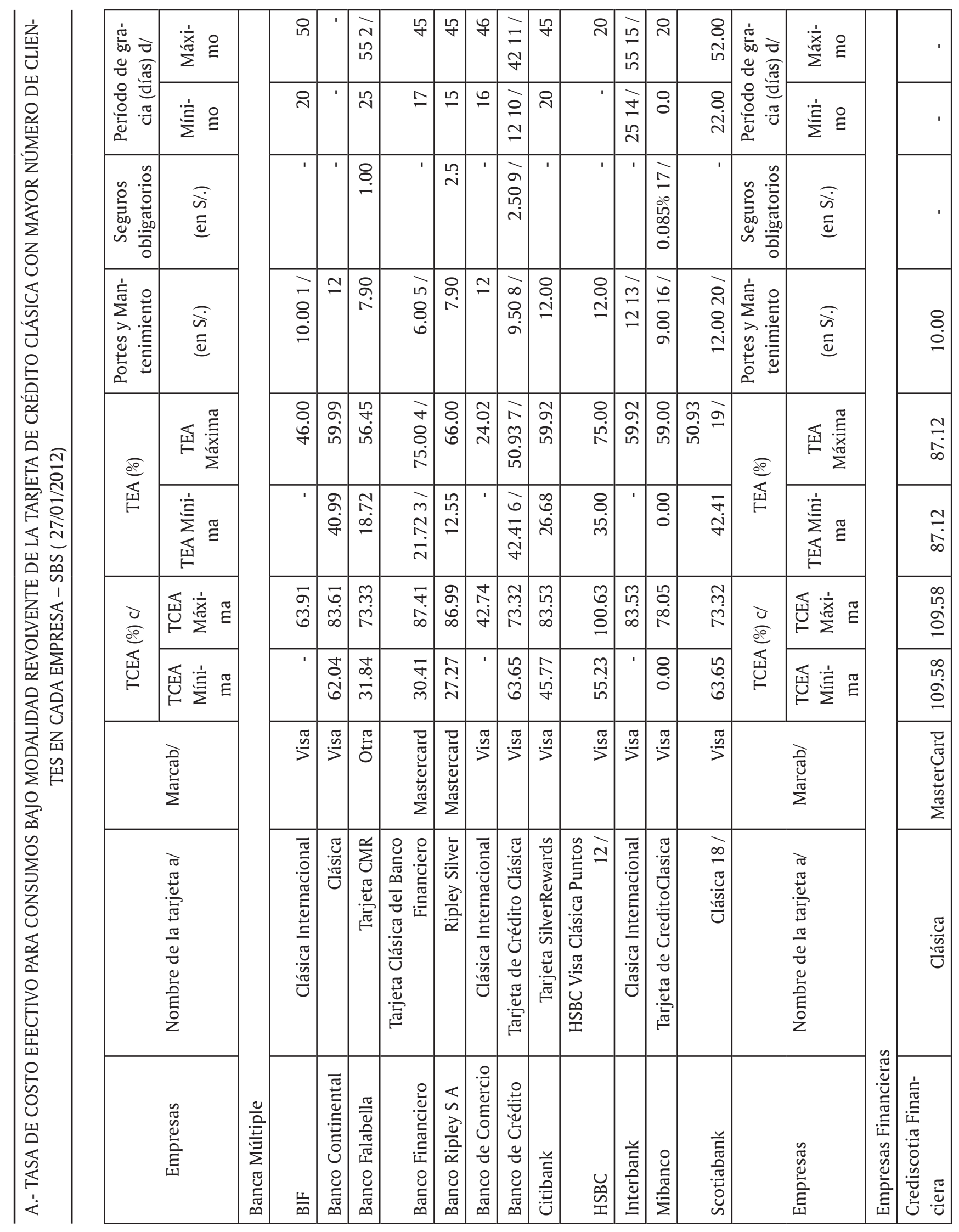




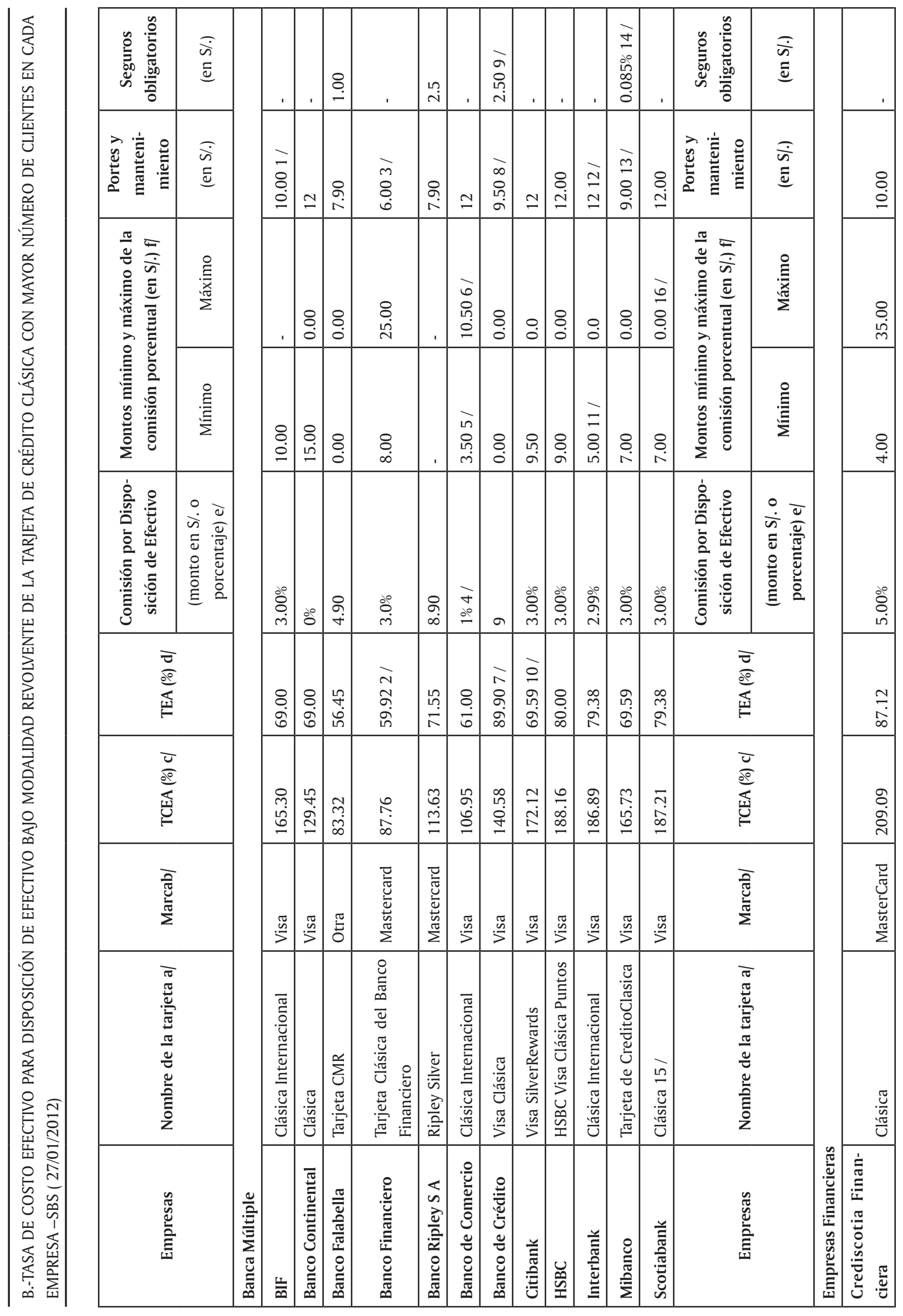


ción para reducir la carga de los tarjetahabientes y evitar al deterioro de la economía familiar. De otro lado, adoptar medidas orientadas a propiciar una mayor competencia de intermediarios, tratar la capacidad de pago real de los usuarios de las TC, todas sus líneas de endeudamientos y la elevada tasa que se cobran por estos préstamos, considerando las expectativas de sus ingresos y transparencia de información de parte de los bancos y financieras que ofertan las TC.

\section{BIBLIOGRAFÍA}

Weston y Copeland; Finanzas en Administración.

Jonson R. y Melicher; . Administración Financiera.

Van Horne; Fundamentos de Administración Financiera.

Van Horne; Administración Financiera

R. Brealey y S. Myers. "Finanzas Corporativas".

Stephen A. Ross. "Fundamentos de Finanzas Corporativas"

D. emery. "Administración Financiera Corporativa".

Lawrence Gitman. "Principios de Administración Financiera".
Ch. T. Horngren; Contabilidad de Costos y Administrativa.

Z. BODIE Y R. MERTON; Finanzas. Editorial Prentice Hall.1999.

R. DOUGLAS Y J. FINNERTY; Administración Financiera corporativa.

Scott Besley - E.F. Brigham. Fundamentos de Administración Financiera.

HUNT, DONALDSON, WILLIAMS... Financiación Básica de los Negocios, UTEHA.

Superintendencia de Banca y Seguros- SBS

Banco Central de Reserva del Perú- BCRP.

Instituto Nacional de Estadística e Informática -INEI ;

Superintendencia de Mercado de Valores- EX CONASEV

Banco Mundial.

Documentos de análisis del Mercado: Invertia, Economática, www.viainversiones.com, Bloomberg, etc 